\title{
A MEMÓRIA DO TELEJORNALISTA BRASILEIRO ATRAVÉS DA HISTÓRIA ORAL
}

\author{
THE MEMORY OF THE BRAZILIAN TV REPORTER \\ THROUGH ORAL HISTORY
}

\begin{abstract}
VALQUÍRIA PASSOS KNEIPP
Jornalista graduada pela UNESP - Bauru, mestre e doutora em Ciências da Comunicação pela Escola de Comunicações e Artes da USP. Professora da UFRN e da Unifor.
\end{abstract}

\section{RESUMO}

Este artigo apresenta a utilização do estatuto da história oral junto com outras possibilidades metodológicas na realização de uma pesquisa qualitativa sobre o telejornalista brasileiro. Através de 37 entrevistados, divididos em décadas, desde a implantação da televisão, em 1950, até os anos 1990, foi possível conhecer um pouco desta trajetória comunicacional. A perspectiva dos profissionais de telejornalismo como colaboradores trouxe, através da memória deles, informações complementares à história da televisão brasileira. A influência americana também foi investigada e avaliada dentro deste processo evolutivo.

Palavras-chave: jornalismo. história oral. Telejornalista. modelo americano.

\section{ABSTRACT}

This article presents the use of the statute of oral history along with other methodological possibilities in conducting qualitative research on the Brazilian TV reporter. Through the 37 respondents, divided into decades since the introduction of television in 1950 until the 1990s, it was possible to know a little of this communication path. The prospect of television journalism professionals as collaborators brought by their memory, additional information to the history of Brazilian television. The American influence was also investigated and evaluated within this evolutionary process.

Keywords: journalism. oral history. TV reporter. American model.

\section{A história oral como instrumental metodológico}

Este artigo pretende apresentar a utilização de alguns conceitos estabelecidos pela história oral, que mesclados com outras ferramentas, constituíram um instrumental metodológico para o desenvolvimento da pesquisa intitulada Trajetória de formação do telejornalista brasileiro. 
A pesquisa propôs uma investigação a respeito de como se deu a trajetória de formação do telejornalista brasileiro, através dos mais de 59 anos de introdução da televisão no Brasil e, ainda, quais foram as implicações causadas pelo modelo americano de telejornalismo dentro deste processo evolutivo. Outra proposta do trabalho foi traçar um perfil para o profissional de telejornalismo do futuro, dentro da TV digital, processo que já foi iniciado no país.

Para o desenvolvimento da pesquisa foram entrevistados 37 telejornalistas, que exerceram ou exercem diversas funções nas redações de telejornalismo, agrupados desde a década de 50 até 90. As entrevistas foram orientadas pelos preceitos estabelecidos pela história oral. Além disso, a pesquisa bibliográfica e o método etnográfico, dentre outros, também foram empregados para complementar o conjunto de possibilidades metodológicas empregadas.

As conclusões do trabalho revelaram durante o processo evolutivo de formação do telejornalista brasileiro, algumas fases distintas, que foram identificadas e catalogadas, de acordo com os momentos históricos, políticos e econômicos ocorridos no país, e que a influência americana existiu e ainda existe.

O método utilizado foi a pesquisa qualitativa, através da utilização de entrevista gravada, que contém um panorama da vida profissional de cada personagem, através da história de vida ou, como também é conhecida, da história oral. De acordo com Meihy (2005, p.17), esta é uma prática de apreensão de narrati- vas feitas através do uso de meios eletrônicos e destinada a recolher testemunhos, promover análises de processos sociais do presente e facilitar o conhecimento do meio imediato. Esta técnica é indicada por se tratar de um assunto amplo e "aberto", de acordo com Thiollent (1980, p. 33), que permitiu, assim, a substituição de um questionário por um simples roteiro de entrevista. Houve uma readequação da premissa básica da história oral, devido às peculiaridades e às proximidades da mesma com jornalismo.

Um roteiro básico para as entrevistas foi desenvolvido e seguido, com informações como: formação, tempo de trabalho, funções exercidas, empresas e atividades desenvolvidas. Mas, em alguns casos, houve alterações em função das próprias histórias que cada personagem se propôs a contar.

Todas as entrevistas foram gravadas em vídeo, com uma câmera mini-dv. Os procedimentos utilizados mostraram-se os mais adequados, devido à atualidade da pesquisa e à diversidade apresentada pelo objeto de estudo, mas foram repensados e ampliados, quando houve necessidade ou possibilidade.

Os dados foram interpretados através do método comparativo, entre uma fase e outra, e também em relação ao que se pretendeu definir como o modelo americano, modelo europeu e o modelo brasileiro. Também foram estabelecidas relações entre as variáveis, como rotina de trabalho, forma de apresentação, forma de produção, forma de edição de texto e imagem, hierarquia dentre as funções, funções exer- 
cidas pelos jornalistas, formação do jornalista, entre outras que se mostraram relevantes e necessárias no decorrer da pesquisa.

Pretendeu-se, na conclusão da pesquisa, apresentar um resumo dos resultados alcançados nos planos teórico, metodológico, temático e prático. Outro objetivo da pesquisa foi expor as possíveis contribuições para o avanço do conhecimento sobre o profissional de televisão e da história da TV.

$\mathrm{O}$ instrumental metodológico selecionado para a elaboração desta pesquisa não foi simples, nem pôde se limitar a um único, mas sim a uma parafernália, com a combinação de vários instrumentos de diversas áreas do conhecimento, como história, sociologia e jornalismo.

$\mathrm{O}$ primeiro deles refere-se ao estatuto defendido pela história oral, que tem por um lado Meihy, com a definição de alguns conceitos. $\mathrm{O}$ número um é a prática de narrativas gravadas por meios eletrônicos (gravadores de áudio e/ou de áudio e vídeo) de testemunhos, com posterior análise. $\mathrm{O}$ número dois prevê a elaboração de documentos, a partir das narrativas colhidas. No número três existe a elaboração de um projeto, com um conjunto de procedimentos. Neste projeto, foi feita a definição de um grupo de pessoas (ou colônia) a serem entrevistadas. No caso desta pesquisa, as colônias foram formadas pelos telejornalistas, através da divisão por década. Também fez parte da pesquisa o planejamento da condução das gravações, transcrição, conferência da fita com o texto, autorização para o uso, arquivamento e, sempre que possível pu- blicação dos resultados, que devem, em primeiro lugar, voltar ao grupo que gerou as entrevistas. $\mathrm{O}$ conceito número quatro propõe o uso de depoimentos gravados e depois transformados em texto, como uma alternativa para o estudo da sociedade. E, finalmente, no conceito número cinco, o uso de entrevistas gravadas e depois transcritas, do oral para o escrito, como um processo sistêmico para o uso de depoimentos (MEIHY, 2005, p. 17 - 18).

Por outro lado, a história oral, através de Freitas, tem outros procedimentos e possibilidades e tem como principal finalidade criar fontes históricas (FREITAS, 2006, p.6). Freitas esclarece, também, a subdivisão que classifica esta pesquisa como história oral temática, pois todos os colaboradores foram entrevistados sobre a (s) sua(s) atuação (ões) como telejornalista (s), portanto:

A entrevista tem caráter temático e é realizada com grupo de pessoas, sobre um assunto especifico. Essa entrevista - que tem característica de depoimento - não abrange necessariamente a totalidade da existência do informante. Dessa maneira, os depoimentos podem ser mais numerosos, resultando em maiores quantidades de informações, o que permite uma comparação entre eles, apontando divergências, convergências de uma memória coletiva, por exemplo, (FREITAS, 2006, p. 8)

Através da História Oral, segundo Meihy, o primeiro passo é o estabelecimento da Comunidade de Destino como sendo os comunicadores, que atuam ou atuaram 
em emissoras de televisão, desde a sua implantação no Brasil, no dia 18 de setembro de 1950, e ain$\mathrm{da}$, os estudantes, professores e pesquisadores de telejornalismo.

Dentro desta Comunidade de
Destino, a Colônia foi formada pelos jornalistas de TV, ou seja, os telejornalistas. As redes foram organizadas por décadas $(50$, $60,70,80$ e 90$)$ e por sexo: masculino e feminino.

\begin{tabular}{|l|l|l|}
\hline Comunidade de destino & Colônias & Redes \\
\hline \multirow{4}{*}{$\begin{array}{l}\text { Comunicadores, estudantes e } \\
\text { pesquisadores }\end{array}$} & 01 Telejornalista & Rede dos anos 50 \\
\cline { 2 - 3 } & 08 Telejornalistas & Rede dos anos 60 \\
\cline { 2 - 3 } & 06 Telejornalistas & Rede dos anos 70 \\
\cline { 2 - 3 } & 18 Telejornalistas & Rede dos anos 80 \\
\cline { 2 - 3 } & 04 Telejornalistas & Rede dos anos 90 \\
\hline
\end{tabular}

\section{As redes de colaboradores}

A área geográfica de cobertura desta pesquisa se restringiu à região sudeste, levando como referenciais os estados de São Paulo e Rio de Janeiro, mas também foi incluída uma amostra em outras regiões, como Pernambuco, Ceará, Minas Gerais e Rio Grande do Sul.

O ponto zero foi o jornalista Gregório Bacic. Ele ajudou na escolha das Redes de entrevistados, que estão, inicialmente, separados por gerações, a partir dos anos 50. A entrevista com o ponto zero aconteceu no dia 21 de setembro de 2005 , e contou com os seguintes questionamentos:

1- Desde quando você trabalha em tevê?

2- Em quais emissoras você já trabalhou?

3- Quais foram as funções que já exerceu?

4- Quais eram as atividades desenvolvidas em cada uma das funções exercidas?

5- Como você avalia a importância do seu trabalho na tevê?
6- Quais eram as características necessárias para se trabalhar na tevê nos anos 60 ?

7- E nos anos seguintes, houve alterações no nível de exigência profissional para a tevê?

8- Comente a sua rotina de trabalho na época.

9- Fale sobre a equipe de trabalho.

10- Fale sobre a hierarquia da redação.

Ao todo, foram cinco Redes de colaboradores, através das gerações, com alguns entrevistados em cada década.

A primeira rede, dos anos 50 - os primórdios na implantação da TV - modelo radiofônico ou rádio com imagens.

A segunda rede, dos anos 60 - influência americana X influência cinematográfica; nos anos 60 , o acordo entre a Rede Globo e o grupo norte-americano Time Life trouxe tecnologia e treinamento aos profissionais da emissora; em paralelo, profissionais oriundos do cinema acabaram trabalhando 
nas emissoras de TV, resultando, o que vai se tentar mostrar, no que foi a influência cinematográfica no telejornalismo brasileiro.

Nos anos 70, na terceira rede - a cópia do modelo americano já estava efetivada, quando o acordo entre a Rede Globo e o grupo Time Life terminou; o telejornalismo já estava reproduzindo exatamente o formato e a linguagem americanos.

A quarta rede, dos anos 80 - houve a valorização do texto, com a vinda dos jornalistas do impresso para a televisão; nesta fase, com a criação de duas novas redes de TV, Manchete e SBT, o modelo americano passou a fazer parte de todas as emissoras.

$\mathrm{Na}$ quinta rede, dos anos $90-$ houve a segmentação dos conteúdos e dos formatos, com a chegada das emissoras em UHF e da tevê a cabo, com os canais de notícias 24 horas e, ainda, as readequações para um modelo latino-americano. Acredita-se que neste período, com a chegada de telejornais, como Aqui Agora, e do primeiro Âncora brasileiro, o telejornalismo recebeu também a influência da América Latina e dividiu a audiência que, até então, era monopolizada pela Rede Globo.

A perspectiva diferencial do entrevistado, através do viés da história oral, apresentou o mesmo acoplado ao projeto como um "colaborador", e não como um simples entrevistado. Isso é um fator essencial para esta história que se pretende contar, pois os livros e as pesquisas jornalísticas já contam e mostram a história oficial sem que se possa perceber a presença e a participação dos envolvidos no processo. A prioridade desta pesquisa foi a experiência individual e a participação efetiva do "colaborador" durante todo o processo. Aqui, a experiência que se pretendeu foi a "da retomada salvadora da palavra de um passado que, sem isso, desapareceria no silêncio e no esquecimento" (FONSECA Apud Benjamin). E, de acordo com Fonseca:

\begin{abstract}
Benjamin distingue a "experiência" - enquanto tradição coletiva, como algo que encontra raízes remotas, como a tradição dos provérbios, do "contar" uma história de pai para filho, como a transmissão da sabedoria dos velhos para os mais novos - da simples "vivência", muito mais fugaz, desapegada e desenraiza$d a$, e que progressivamente vai substituindo a primeira. (FONSECA Apud Benjamin)
\end{abstract}

Assim sendo, muitos colaboradores se colocaram também, como parte integrante da pesquisa, e indicaram novos entrevistados, que poderiam ajudar com seus depoimentos.

A primeira Rede de colaboradores dos anos 50 - início da implantação da TV (rádio com imagens), contou com um único entrevistado, Mário Fanucchi. O critério de seleção utilizado foi em função das pessoas que puderam ser encontradas, pois boa parte dos jornalistas da época já faleceu, devido à faixa etária, em torno de 70 ou 80 anos de idade. O questionário utilizado foi:

1- Como você foi trabalhar na tevê?

2- Que tipo de experiência era necessária para o trabalho? 
3- Como era o trabalho do jornalista naquela época?

4- Quais as funções que desempenhou nos cargos que ocupou?

5- Comente o processo de elaboração de um telejornal?

6- Conte histórias da (s) emissoras em que trabalhou.

A segunda Rede de colaboradores, dos anos 60 - fase cinematográfica, contou com os seguintes entrevistados: Clélia Cardim, Demétrio Costa, Fernando Pacheco Jordão, Luiz Fernando Mercadante, Paulo Roberto Leandro, Fernando Barbosa Lima, Carlos Alberto Ballut Vizeu e Fabbio Peres. O critério de seleção buscou encontrar profissionais que tivessem trabalhado nas diversas emissoras existentes na época, mas teve que ser readequado no caso de alguns entrevistados que não concordaram ou não estavam acessíveis, como, por exemplo, Alice Maria e Armando Nogueira. O questionário utilizado foi:

1- Como você trabalhar na tevê?

2- Qual era a experiência que possuía?

3- Como era o trabalho diário?

4- Qual era a hierarquia da redação?

5- Conte histórias de trabalho.

A terceira Rede de colaboradores, dos anos 70 - cópia e adoção do modelo americano, teve os seguintes colaboradores: Sandra Passarinho, João Batista de Andrade, Laurindo Leal Filho, Sebastião Squirra, Gregório Bacic e Eduardo Coutinho. $\mathrm{O}$ critério de seleção balizou-se pelas funções exercidas por cada profissional e a relevância do trabalho realizado. $\mathrm{O}$ questionário utilizado teve o mesmo conteúdo da rede anterior. Os jornalistas Laurindo Leal Filho e Sebastião Squirra também atuaram e atuam como professores de telejornalimo. Alguns jornalistas não concederam entrevista, por falta de espaço na agenda, como Neusa Rocha, Carlos Nascimento e Mônica Waldvogel.

A quarta Rede de colaboradores, dos anos 80 - valorização do texto, teve a participação dos seguintes colaboradores: Edson Higo do Prado, José Maria Santana, Luiz Antonio Malavolta, Luiz Carlos Azenha, Marco Nascimento, Alfredo Vizeu, Vanessa Kalil, Luiz Gonzáles, Silvia Poppovic, Nelson Hoineff, Carmen Amorin, Marcos Gomide, Amauri Sérgio Soares, Alceu Nader, Caco Barcellos, Celso Pelosi, José Carlos Aronchi de Souza e Paulo Markun. O critério de seleção buscou encontrar profissionais que tivessem exercido as diferentes funções já estabelecidas como editor de texto, repórter, chefe de reportagem, chefe de redação e diretor de jornalismo. $\mathrm{O}$ questionário utilizado teve o mesmo conteúdo da segunda rede e ainda outro específico para professores de telejornalismo (como Alfredo Eurico Vizeu), a saber:

1- Como você foi lecionar telejornalismo?

2- Que tipo de experiência era necessária para ensinar esta disciplina?

3- Como você se tornou professor de telejornalismo (cursos/ especialização/ mestrado/ doutorado)?

4- Como eram as aulas de telejornalismo quando você começou lecionar? 
5- Qual a metodologia você adotou para ensinar os conhecimentos práticos?

6- As aulas eram mais teóricas ou práticas?

7- Quais os autores (bibliografia) que você adotou?

8- Quais os equipamentos disponíveis na universidade para que os alunos pudessem praticar telejornalismo?

9- Como era feita a avaliação dos alunos? Baseava-se em teoria ou em prática.

10- Comente o processo de elaboração de um telejornal na universidade?

11- Que tipo de exercício prático os alunos desenvolviam?

12- Em sua opinião o telejornalismo brasileiro copiou o modelo americano e mantém até hoje? Por quê?

13- Conte histórias da (s) universidade (s) que trabalhou?

Nesta rede ainda, alguns nomes de relevância, como a jornalista Vera Íris Paternostro, não atenderam às muitas solicitações de entrevista.

A quinta Rede de colaboradores, dos anos 90 - a segmentação dos conteúdos e dos formatos, contou com os seguintes colaboradores: Alberto Luchette, Amilcare Dalevo, Rodrigo Vianna e Jacqueline Rodrigues. O critério de seleção baseou-se nas principais emissoras de tevê aberta e segmentada, de acordo com a audiência e existência de departamento de jornalismo. O questionário utilizado teve o mesmo conteúdo da segunda rede. Alguns jornalistas também ficaram sem prestar depoimento, por falta de interesse ou de agenda, como no caso de Humberto Candil,
Marcos Humel e Fátima Bernardes.

Estas cinco redes de colaboradores não foram únicas e nem absolutas. Elas estiveram sempre em transformação, devido a fatores como dificuldade de encontrar os jornalistas, a falta de interesse dos mesmos em participar e até mesmo falta de condições físicas e de tempo.

Os entrevistados também foram estimulados a indicar nomes, através da técnica da bola de neve, que de acordo com a necessidade da pesquisa, também foram incorporados ao trabalho por sugestão dos colaboradores.

A metodologia da História Oral, segundo Meihy (2005), "não procura a verdade, mas a experiência" traz uma perspectiva dialética, com base em três momentos, após a entrevista: na primeira fase, a transcrição literal da entrevista gravada por meio eletrônico; na segunda fase, a textualização, que consiste basicamente na retirada das perguntas; e numa terceira, denominada de transcriação, onde se fará um rearranjo do texto, pois para o autor, "na tradução do oral para o escrito não é possível traduzir sem mudança" (MEIHY, 2005).

Uma etapa posterior consiste na negociação com o colaborador, onde o texto é apresentado para ele, para que o mesmo possa autorizar ou opinar, em parceria com o pesquisador, sobre o que e como deve ser apresentado o material final. Esse processo não foi levado a cabo, pelo menos até o encerramento da pesquisa, pois não haveria espaço para o texto transcriado no corpo da tese, em face do grande número de entrevistados, com gravações que va- 
riaram de vinte e cinco minutos no mínimo, até uma hora e meia. Colocando no papel houve uma variação de cinco até oito laudas transcritas, por entrevistado.

\section{Outras ferramentas do instrumental metodológico}

Ainda no aspecto metodológico, vem a importante contribuição da sociologia, através do método etnográfico, que também não pôde ser usado de forma contínua, mas somente na etapa que se refere à época atual, quando já se está preparando o telejornalista para a tevê digital.

O método etnográfico, de acordo com Travancas (TRAVANCAS, 2005, p. 95), consiste em estabelecer relações, selecionar informantes, transcrever textos, levantar genealogias, mapear campos, manter um diário, entre outras medidas. Nesta pesquisa, em cada entrevista, buscou-se o resgate de textos e materiais guardados pelos entrevistados, a indicação de novos entrevistados e, através do próprio depoimento, mapear a trajetória do telejornalista. A etnografia, como parte do trabalho de campo, trata-se de uma pesquisa qualitativa, pois permite uma aproximação com o objeto, conforme propõe Travancas:

Ela exige um 'mergulho' do pesquisador, ou seja, não é um tipo de pesquisa que pode ser realizada em um período muito curto e sem preparo. É fundamental, como etapa anterior à etnográfica propriamente dita, um levantamento bibliográfico sobre o tema (TRAVANCAS, 2005, p. 100).
Do jornalismo, vem a concepção básica deste trabalho, pois a vivência jornalística propõe a entrevista como um método muito importante e revelador. Mas, como se trata de um trabalho científico, com fins reflexivos, a tipificação para as entrevistas realizadas foi o que Duarte e Barros (2005)chama de entrevista em profundidade (grifo meu), pois: "a entrevista em profundidade é a técnica qualitativa que explora um assunto, a partir da busca de informações, percepções e experiências de informantes, para analisá-las e apresentá-las de forma estruturada" (TRAVANCAS, 2005, p. 62). Esta abordagem permite maior liberdade, tanto para o entrevistado, quanto para o entrevistador. Neste caso, o objetivo do uso da entrevista em profundidade é a descrição do processo de trabalho no qual o entrevistado está ou esteve envolvido durante algum tempo.

A entrevista em profundidade pode ser aberta, semi-aberta ou fechada, segundo Duarte e Barros (2005). No caso específico desta pesquisa, a tipificação escolhida foi a semi-aberta, por se julgar mais compatível com os objetivos a serem atingidos e também por identificar a existência de um roteiro de controle, podendo ser adaptado ou alterado, de acordo com o entrevistado. Outro motivo para esta escolha é a utilização livre do roteiro, pois ele permite a comparação das respostas e articulação dos resultados, auxiliando a sistematização das informações fornecidas por diferentes entrevistados (TRAVANCAS, 2005, p.67).

A seleção dos entrevistados procedeu-se através de uma mes- 
cla entre os dois tipos básicos de amostras não probabilísticas para o uso em entrevistas qualitativas, que Duarte e Barros (2005) denomina de: por conveniência ou intencional. Segundo eles, a seleção por conveniência, também chamada acidental, "é baseada na viabilidade. Ocorre quando as fontes são selecionadas por proximidade ou disponibilidade". Em alguns casos, critérios como a proximidade da pesquisadora com os profissionais e a disponibilidade dos mesmos, ajudaram na seleção e na aceitação em participar de uma pesquisa acadêmica. Por outro lado, também houve a seleção intencional, "quando o pesquisador faz a seleção por juízo particular, como conhecimento do tema ou representatividade subjetiva" (TRAVANCAS, 2005, p. 69), pois a experiência profissional e a pesquisa bibliográfica proporcionaram o conhecimento do tema, a ponto de determinar, intencionalmente, alguns entrevistados essenciais ao trabalho.

Mesmo sendo considerada por Moreira in Travancas (2005) como uma fonte secundária, a análise documental também é um recurso, que, neste caso, ajudou no resgate da história dos telejornais brasileiros. Pois, numa fase posterior da pesquisa de campo, houve uma consulta a documentos oficiais, a respeito da concessão de canais de televisão no Brasil (TRAVANCAS, 2005, p. 270). Este método "como explica a própria designação documental, compreende a identificação, a verificação e a apreciação de documentos para determinado fim" (TRAVANCAS, 2005, p. 271). Neste caso, o uso desta técnica ou método visa complementar as informações conseguidas por outras formas.

\section{Algumas considerações}

Ao se trabalhar uma pesquisa em comunicação, que buscou, através da memória, resgatar fatos para compor uma parcela da trajetória de formação do telejornalista brasileiro, o instrumental metodológico adequado foi de suma importância. Com elementos como a história oral, a etnografia, as entrevistas em profundidade e a pesquisa bibliográfica foi possível explorar as qualidades que cada um deles pôde proporcionar, e em alguns momentos, adaptá-los às necessidades do objeto de pesquisa.

A pesquisa bibliográfica contribuiu com a perspectiva que havia sido registrada anteriormente por outros pesquisadores do campo da comunicação e do subcampo da televisão, que inclui o telejornalismo. Foi importante conhecer todo o trajeto percorrido por outros pesquisadores para a realização de um trabalho autêntico.

Através do estatuto parcial da história oral foi possível planejar, organizar e realizar uma aproximação com as fontes primárias de colaboradores. Esse processo proporcionou autenticidade e humanização ao processo da pesquisa.

A noção de etnografia, como parte do trabalho de campo da pesquisa, proporcionou, conforme Travancas, um verdadeiro mergulho dentro do universo da trajetória profissional do telejornalismo brasileiro.

A entrevista em profundidade 
trouxe o ponto alto da pesquisa, pois, através da experiência dos profissionais e de suas próprias trajetórias, se pôde acrescentar informações qualitativas à própria história da televisão brasileira.

Através da utilização do ins- trumental metodológico aqui apresentado foi possível constatar que a influência americana esteve presente em toda trajetória de formação do telejornalista brasileiro e, ainda, nos dias de hoje pode-se notar traços marcantes da mesma.

\section{Referências}

DUARTE, Jorge e BARROS, Antonio (Orgs.). Métodos e Técnicas de Pesquisa em Comunicação. São Paulo: Editora Atlas, 2005.

FONSECA, Ricardo Marcelo. Walter Benjamin: a temporalidade e o direito. Disponível em: http://www.historiadodireito.com.br.

FREITAS, Sônia Maria de. História Oral: procedimentos e possibilidades. São Paulo: e-book, 2006.

LOPES, Maria Immacolata Vassalo de. Pesquisa em Comunicação: Formulação de um modelo metodológico. São Paulo: Loyola, 1994.

MEIHY, José Carlos Sebe Bom. Manual de História Oral. São Paulo: Edições Loyola, 2005.

THIOLLENT, Michel J. M. Crítica metodológica, investigação social \& enquête operária. Polis, 1980.

TRAVANCAS, Isabel. Fazendo etnografia no mundo da comunicação. In: Duarte e Barros, Atlas, 2005.

Data do Recebimento: 15/03/2009

Data do Aceite: 20/04/2009 